\title{
Bipolar spectrum disorders and associated factors among adults attending an antiretroviral therapy clinic in Gedeo zone health centers, southern Ethiopia
}

This article was published in the following Dove Medical Press journal: Neuropsychiatric Disease and Treatment

\section{Zelalem Belayneh' \\ Wagaye Alemu \\ Birhanie Mekuriaw' \\ Zegeye Abebe ${ }^{3}$}

'Department of Psychiatry, College of Health and Medical Science, Dilla University, Dilla, Ethiopia; ${ }^{2}$ Department of Epidemiology and Biostatistics, College of Health and Medical Science, Dilla University, Dilla, Ethiopia; ${ }^{3}$ Department of Human Nutrition, Institute of Public Health, College of Medicine and Health Sciences, University of Gondar, Gondar, Ethiopia
Correspondence: Zelalem Belayneh Department of Psychiatry, College of Health and Medical Science, Dilla University, Dilla, Ethiopia Email zelalembe45@gmail.com
Background: Bipolar spectrum disorders (BPSDs) are more common among HIV-positive individuals than the general population. Although BPSDs have very diverse and devastating consequences (immune suppression, cognitive impairment and poor medication adherence), little is known about BPSDs among HIV-positive individuals in Ethiopia. Therefore, this study was aimed to assess the prevalence and associated factors of BPSDs among adults attending antiretroviral therapy (ART) clinics in Gedeo zone health centers, southern Ethiopia.

Patients and methods: An institutional-based cross-sectional study was conducted by screening 412 randomly selected HIV-positive individuals using Mood Disorder Questionnaire. SPSS version 20 was used for data analysis. Bivariable and multivariable logistic regression models were fitted to identify factors associated with BPSDs. Adjusted OR (AOR) with corresponding 95\% CI was computed to determine the association.

Results: Of the total 412 participants, $11.2 \%$ were screened positive for BPSDs. Lower CD4 count $(\mathrm{AOR}=2.97 ; 95 \% \mathrm{CI}: 1.11,7.90)$, past history of mental health problem $(\mathrm{AOR}=3.35$; 95\% CI: $1.576,7.144)$, poor social support $(\mathrm{AOR}=2.6$; $95 \% \mathrm{CI}: 1.06,6.63)$ and poor ART drug adherence $(\mathrm{AOR}=3.59 ; 95 \% \mathrm{CI}: 1.78,7.21)$ had a positive association with BPSDs.

Conclusion: In this study, the prevalence of BPSDs was high among adult patients attending ART clinics in Gedeo zone health centers. Poor social support, poor ART drug adherence, lower CD4 level and history of mental illness had statistically significant association with BPSDs. This demonstrates a need for the integration of Mental Health and Psycho Social Support with HIV/AIDS care services. Moreover, establishing good social support and controlling ART adherence were found to be very crucial too.

Keywords: bipolar spectrum disorder, HIV/AIDS, mental health, Ethiopia, mood disorders, Gedeo, Dilla

\section{Introduction}

Bipolar spectrum disorder (BPSD) is a cluster of severe psychiatric illnesses characterized by alternating manic and depressed mood states with associated disturbances in energy levels, sleep, appetite, increased libido and cognition. ${ }^{1}$ According to the WHO 2008 report, >29.5 million persons are living with BPSD globally. It was also estimated as the seventh leading cause of non-fatal burden of diseases. ${ }^{1-3}$ The lifetime prevalence of BPSDs ranges from $2.4 \%$ to $15.1 \%$ in the general population. ${ }^{4}$ But this figure increases to high rates among HIV-positive individuals. ${ }^{5-7}$

Manic and hypomanic episodes of BPSDs are characterized by a period of time where the patient has an elevated, expansive or irritable mood, and some typical symptoms such as elevated self-esteem, disinhibition and hypersexuality are present. ${ }^{8}$ 
In addition, people with BPSDs have higher rates of alcohol and illicit drug abuse, ${ }^{9}$ which increase the risk of further HIV transmission due to the impulse control difficulty of BPSDs. ${ }^{10-12}$ HIV-positive individuals with BPSD also appear to be at a higher risk for engagement in behaviors associated with transmission of HIV due to the episodic nature and sexual arousal effects of the disorder. ${ }^{10,13,14}$

Studies showed that HIV-positive individuals with comorbid bipolar disorders were less likely to be antiretroviral therapy (ART) adherent ${ }^{15,16}$ and were at high risk of immune suppression, ${ }^{17,18}$ other opportunistic infections and mental health problems. ${ }^{19}$ Thus, BPSDs are very complex and need a holistic approach to understand them. ${ }^{20}$

The origin and interdependency in terms of switching from one subtype to another and the treatment response are also amazingly interesting in the area of bipolar disorders. ${ }^{21}$ However, the focus of most studies is on bipolar I disorder, which is the most severe form of the BPSDs, and therefore, the large group of BPSDs whose prevalence ranges from 3\% to $5 \%$ is neglected. ${ }^{22-24}$ By taking this into consideration, the current study was aimed to assess BPSDs and associated factors among adults attending ART clinics of Gedeo zone health centers.

\section{Patients and methods Study design and setting}

An institutional-based cross-sectional study was conducted among adult patients attending ART clinic in Gedeo zone health centers from April 1 to May 12017 . Gedeo zone is found in South Nation Nationality and Peoples' Regional States of Ethiopia, $359 \mathrm{~km}$ southeast of Addis Ababa (the capital city of Ethiopia). In the zone, there are about 39 health centers, and only 7 of them provide ART service. All the health centers had no mental health professionals during the data collection period.

\section{Sample size determination and sampling procedure}

The assumptions made for sample size calculation were a 95\% CI and 50\% expected prevalence of BPSDs to get the maximum sample size and a 5\% margin of error. The systematic random sampling method was employed to select the study participants. Initially, the expected total number of adult patients attending the ART clinic during the study period was calculated. Then, the number of adult patients included in each health center was determined based on the proportionate population size. The sampling interval $(\mathrm{K})$ was determined by dividing the total number of adult patients attending the ART clinic from each health center by the sample size to be drawn from that health center. To determine the starting point, lottery method was used to select one adult patient between one and K. Subsequently, the K value was added until the sample size allocated to each health center was reached.

\section{Data collection instruments and procedures}

The data were collected by five trained psychiatric nurses supervised by two MSc mental health professionals. Interviewer-administered questionnaire was used to collect data. The questionnaire was translated into Amharic and Gedeu'fa (the commonly spoken languages in the study area) and finally back to English to check its consistency. The translated questionnaire was pre-tested among $22(5 \%)$ patients attending ART clinic at Chuko health center (not included in the study) and minor modification was done. The questionnaire had six parts, consisting of sociodemographic characteristics, Oslo-3 social support scale, HIV/ AIDS-related factors, Morisky medication adherence scale, Alcohol Use Disorders Identification Test (AUDIT) and Mood Disorder Questionnaire (MDQ) tool.

The outcome variable (BPSD) was measured using the MDQ tool. The MDQ consists of three parts including 13 Yes/No questions to assess the presence of symptoms and behaviors related to mania/hypomania as per the Diagnostic and Statistical Manual of Mental Disorders, Fifth Edition criteria and clinical experience. Additionally, two more questions were asked for screening purpose. The first question was to inquire about the co-occurrence of the defined symptoms and the second was about the severity of the symptoms (ranging from "no problem" to "serious problem"). The MDQ is a structured questionnaire used to assess BPSDs in many clinical studies. ${ }^{25,26}$ The tool has been found to have good reliability and validity for the screening of BPSDs with a sensitivity and specificity of 0.90 and 0.88 , respectively. ${ }^{27-30}$

In this study, individuals were considered positive for BPSDs when the following condition was satisfied: if individuals responded "yes" for seven or more symptoms among the first 13 "Yes" or "No" questions, and the co-occurrence of the symptoms and the severity of symptoms was either moderate or serious. ${ }^{30,31}$

The level of alcohol consumption among respondents was measured using the AUDIT. AUDIT is a screening instrument for alcohol use disorder including harmful or hazardous alcohol use and alcohol dependence. ${ }^{32,33}$ AUDIT is a 10-item questionnaire, which covers the domains of alcohol consumption, drinking behavior and alcohol-related 
problems. Responses of each question are scored from 0 to 4 , giving a maximum possible score of 40 . A score of 8 or more is associated with harmful or hazardous drinking. ${ }^{34}$

The respondent's social support level was assessed by Oslo-3 social support scale, which has been used in different studies and has a good reliability. ${ }^{14}$ Similarly, Morisky 4-item medication adherence scale was used to assess the level of ART adherence. ${ }^{49} \mathrm{HIV} /$ AIDS-related characteristics such as year of follow-up, clinical stage and recent CD4 level were collected from the clinical records of the hospital.

\section{Data processing and analysis}

First, the data were checked for their completeness and consistency. Then, they were coded and entered into the computer using EPi Info version-5 software and transformed into SPSS version 20 for analysis. Descriptive statistics were carried out to measure the magnitude and distribution of BPSDs, and the result was presented using text and tables. Bivariable and multivariable analyses were fitted to identify factors associated with BPSDs. Variables with a $P$-value of $<0.25$ in the bivariable analysis were also fitted into the multivariable logistic regression analysis. In multivariable analysis, variables with a $P$-value of $<0.05$ were considered statistically significant. Adjusted OR with the corresponding $95 \%$ CI was calculated to show the strength of the association.

\section{Ethics approval and consent to participate}

Ethical clearance was obtained from Dilla University, and a supportive letter was secured from Gedeo zone Health Department Office. Written informed consent was obtained from each participant after a brief explanation was given to them about the scope and objectives of the study prior to the interview. Personal identifiers such as name and phone numbers of the study participants had never been recorded for the purpose of anonymity. The collected information was kept confidential and used only for the purpose of study.

\section{Results}

\section{Sociodemographic characteristics of respondents}

A total of 412 participants were included in this study, with a response rate of $97.3 \%$. The mean $( \pm \mathrm{SD})$ age of the respondents was $31( \pm 8.9)$ years. More than a quarter $(28.6 \%)$ of the participants was within the age range of 43-54 years, and $58.7 \%$ were females. Regarding the marital status of participants, $31.7 \%$ were divorced and only $23.5 \%$ were married and living together (Table 1).
Table I Sociodemographic characteristics of patients attending ART clinic in Gedeo zone health centers, southern Ethiopia, 2017 $(\mathrm{N}=4 \mid 2)$

\begin{tabular}{|c|c|c|}
\hline Variables & Frequency & Percentage \\
\hline \multicolumn{3}{|l|}{ Age in years } \\
\hline $18-30$ & 106 & 25.7 \\
\hline $31-42$ & 81 & 19.7 \\
\hline $43-54$ & 118 & 28.6 \\
\hline $55-65$ & 107 & 26.0 \\
\hline \multicolumn{3}{|l|}{ Sex } \\
\hline Male & 170 & 41.3 \\
\hline Female & 242 & 58.7 \\
\hline \multicolumn{3}{|l|}{ Residency } \\
\hline Rural & 138 & 33.5 \\
\hline Town & 274 & 66.5 \\
\hline \multicolumn{3}{|l|}{ Religion } \\
\hline Orthodox & 64 & 15.5 \\
\hline Muslim & 139 & 33.7 \\
\hline Protestant & 183 & 44.4 \\
\hline Others ${ }^{a}$ & 26 & 6.3 \\
\hline \multicolumn{3}{|l|}{ Ethnicity } \\
\hline Gedeo & 138 & 33.5 \\
\hline Oromo & 119 & 28.9 \\
\hline Amhara & 87 & 21.1 \\
\hline Guragie & 48 & 11.7 \\
\hline Others ${ }^{b}$ & 20 & 4.9 \\
\hline \multicolumn{3}{|l|}{ Marital status } \\
\hline Married & 97 & 23.5 \\
\hline Single & 85 & 20.6 \\
\hline Divorced & 129 & 31.3 \\
\hline Widowed & 101 & 24.5 \\
\hline \multicolumn{3}{|l|}{ Educational status } \\
\hline Unable to read and write & 54 & 13.1 \\
\hline Able to read and write & 99 & 24.0 \\
\hline Primary & 155 & 37.6 \\
\hline Secondary & 53 & 12.9 \\
\hline Diploma and above & 51 & 12.4 \\
\hline
\end{tabular}

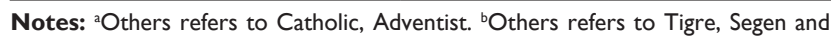
Sidama.

Abbreviation: ART, antiretroviral therapy.

\section{Clinical characteristics of the study participants}

Among the study participants, around $41 \%$ had poor ART medication adherence. About $77.9 \%$ had hazardous levels of alcohol consumption. Regarding the clinical stage, $38.3 \%$ of the respondents were within the WHO clinical stage III and about $40.8 \%$ had CD 4 count between 200 and 500 cells $/ \mathrm{mL}^{3}$. Around $27 \%$ and $16.5 \%$ of the participants had poor social support and past history of mental health problems, respectively. 
Table 2 Factors associated with bipolar spectrum disorders among patients attending ART clinic in Gedeo zone health centers, southern Ethiopia, $2017(\mathrm{~N}=412)$

\begin{tabular}{|c|c|c|c|c|}
\hline \multirow[t]{2}{*}{ Variables } & \multicolumn{2}{|c|}{ MDQ status } & \multirow[t]{2}{*}{ Crude OR $(95 \% \mathrm{Cl})$} & \multirow[t]{2}{*}{ Adjusted OR $(95 \% \mathrm{CI})$} \\
\hline & Positive & Negative & & \\
\hline \multicolumn{5}{|l|}{ Educational level } \\
\hline Unable to read and write & 10 & 44 & $2.09(0.66,6.60)$ & $2.32(0.65,8.24)$ \\
\hline Able to read and write & 7 & 92 & $0.70(0.21,2.32)$ & $0.61(0.16,2.26)$ \\
\hline Primary & 15 & 140 & $0.98(0.34,2.86)$ & $0.80(0.25,2.56)$ \\
\hline Secondary & 9 & 44 & I.88 $(0.58,6.05)$ & $\mathrm{I} .4 \mathrm{I}(0.37,5.34)$ \\
\hline Diploma and above & 5 & 46 & 1.00 & 1.00 \\
\hline \multicolumn{5}{|l|}{ Residency } \\
\hline Town & 26 & 248 & 1.00 & 1.00 \\
\hline Rural & 20 & 118 & $\mathrm{I} .6 \mathrm{I}(0.86,3.0 \mathrm{I})$ & $1.45(0.70,3.00)$ \\
\hline \multicolumn{5}{|l|}{ Years of follow-up } \\
\hline$<5$ & 28 & 140 & $2.5 \mathrm{I}(1.33,4.70)$ & I.79 $(0.87,3.7 \mathrm{I})$ \\
\hline$\geq 5$ & 18 & 226 & 1.00 & 1.00 \\
\hline \multicolumn{5}{|l|}{ CD4 level (cells/mL³) } \\
\hline$<200$ & 24 & 99 & $3.94(1.63,9.55)$ & $2.97(1.11,7.90)^{*}$ \\
\hline $200-500$ & 15 & 153 & $1.59(0.63,4.04)$ & $\mathrm{I} .60(0.60,4.28)$ \\
\hline$\geq 500$ & 8 & 114 & 1.00 & 1.00 \\
\hline \multicolumn{5}{|l|}{ History of mental illness } \\
\hline No & 29 & 315 & 1.00 & 1.00 \\
\hline Yes & 17 & 51 & $3.63(1.85,7.06)$ & $3.35(1.57,7.14)^{* *}$ \\
\hline \multicolumn{5}{|l|}{ Social support } \\
\hline Poor & 21 & 89 & $2.80(1.22,6.43)$ & $2.65(1.06,6.63)^{*}$ \\
\hline Moderate & 16 & 170 & I.II $(0.47,2.62)$ & $1.21(0.48,3.03)$ \\
\hline Strong & 9 & 107 & 1.00 & 1.00 \\
\hline \multicolumn{5}{|l|}{ Drug adherence } \\
\hline Good adherence & 18 & 251 & 1.00 & 1.00 \\
\hline Poor adherence & 28 & 115 & $3.39(1.82,6.38)$ & $3.59(1.78,7.21)^{* * *}$ \\
\hline \multicolumn{5}{|l|}{ Alcohol consumption } \\
\hline Non-hazardous & 30 & 291 & 1.00 & 1.00 \\
\hline Hazardous & 16 & 75 & $2.06(2.06,1.07)$ & $1.92(0.91,4.04)$ \\
\hline
\end{tabular}

Note: $* P<0.05, * * p<0.01$, $* * * p<0.001$.

Abbreviations: ART, antiretroviral therapy; MDQ, Mood Disorder Questionnaire.

\section{Prevalence of BPDs and factors associated with BPSD}

Of the total 412 participants, $11.2 \%$ screened positive for BPSDs. Among these, $60.8 \%$ had $<5$ years of follow-up visit and $63 \%$ had past psychiatric complaints. About $50 \%$ of the participants with stage IV WHO clinical stage of AIDS had BPSDs. The prevalence rates of BPSDs among individuals with poor ART drug adherence and hazardous alcohol drinking were $50 \%$ and $34.7 \%$, respectively.

Based on the result of bivariable analysis, educational level, residency, years of follow-up, CD4 level, history of mental illness, social support, drug adherence and alcohol consumption were candidates for multivariable analysis. In the multivariable analysis, lower CD4 count, past history of mental health, poor social support and poor ART drug adherence had statically significant association with BPSDs (Table 2).

\section{Discussion}

Studies reported that the estimated prevalence of bipolar disorders ranges from $2.4 \%$ to $15.1 \%$ in the general population, but it is expected to be higher among HIV-positive individuals than the general population. ${ }^{4}$ Findings from the current study showed that the prevalence of BPSDs among patients attending ART clinic was $11.2 \%$ with $95 \%$ CI being $8.5 \%-14.1 \%$. This finding is in line with another similar study conducted in Brazil (13.2\%) ${ }^{5}$ and the National Epidemiologic Survey $(10.8 \%) .{ }^{35}$ However, this finding is higher than the finding 
from Maryland (8\%). ${ }^{7}$ This discrepancy might be explained by the difference in the study tools used to assess BSPDs. This study used MDQ, which has a potential to screen other clinical and subclinical BPSDs in addition to mania. ${ }^{36}$

The current study showed a lower prevalence of BPSD than those reported in studies conducted in California $(14.2 \%)^{37}$ and Uganda (43.2\%). ${ }^{38}$ This difference might be due to sociocultural difference of the study population and the special focus of these studies on the mild forms of bipolar disorders (bipolar II and cyclothymic disorder), which might be observed even among relatively normal individuals. ${ }^{5}$

It is documented that advanced HIV disease and lower CD4 count are associated with BSPD. ${ }^{43,44}$ This study confirmed that HIV/AIDS patients with CD4 count $<200$ cells/ $/ \mathrm{mL}^{3}$ had 2.97 times increased risk of developing BSPDs compared to individuals having a CD4 count greater than 500 cells $/ \mathrm{mL}^{3}$. This is due to the neuropsychiatric complications of advanced HIV diseases, which may be due to the direct or indirect effects of HIV on the brain, opportunistic infections or the effects of stress and depression due to being positive for HIV/AID. ${ }^{39,40}$

In this study, the risks of developing BPSDs among clients with poor social support were 2.65 times higher as compared to their counterparts. This finding is supported by other previous studies. ${ }^{41,42}$ The possible explanation is that strong social support is a protective factor and good prognostic indicator of BPSD. ${ }^{43,44}$

Similarly, the risk of developing BPSD among participants with past history of mental illness was 3.35 times higher than those without past history of mental illness. This idea is supported by other studies, indicating that it is due to the high comorbidity and episodic nature of the illness. ${ }^{45,46}$

Finally, the risk of developing BPSD among poor ART drug-adherent individuals was 1.7 times higher as compared to their counterparts. The finding is in line with other studies. ${ }^{47,48}$ This might be due to the protection afforded by ART drugs from neuropathologic penetration of HIV and opportunistic infection in the brain. In addition, ART drugs can improve the quality of life of HIV patients. ${ }^{47,48}$

\section{Conclusion}

This study showed that the prevalence of BPSDs was high among adult patients attending ART clinics in Gedeo zone health centers. Poor social support, poor ART drug adherence, lower CD4 level and history of mental illness had statistically significant association with BPSDs. This demonstrates a need for the integration of Mental Health and Psycho Social Support with HIV/AIDS care services. Moreover, establishing good social support and controlling ART adherence are very crucial too.

\section{Limitations}

This study assessed the prevalence and associated factors of BPSDs including all health centers in the study area. But it has some limitations. First, MDQ is a screening tool for BPSDs in gross and the diagnosis of specific BPSDs has never been attempted. This might overestimate the prevalence of BPSDs. Second, the cross-sectional nature of the study may not show the direct cause and effect relationship.

\section{Data sharing statement}

All the data included in the manuscript can be accessed from the corresponding author Zelalem Belayneh upon request through email at zelalembe45@gmail.com.

\section{Acknowledgments}

The authors would like to acknowledge Dilla University for ethical clearance. The authors would also like to thank the study participants, data collectors and all staffs working at Gedeo zone health center for their dedicated cooperation. Finally, the authors would like to acknowledge Australian and New Zealand Journal of Psychiatry as the abstract of this paper was presented as "Poster Abstracts" in a conference and the Poster Abstracts were published in Australian and New Zealand Journal of Psychiatry.

\section{Author contributions}

All authors contributed to data analysis, drafting or revising the article, gave final approval of the version to be published, and agree to be accountable for all aspects of the work.

\section{Disclosure}

The authors report no conflicts of interest in this work.

\section{References}

1. Kessler RC, Aguilar-Gaxiola S, Alonso J, et al. The global burden of mental disorders: an update from the WHO World mental health (WMH) surveys. Epidemiol Psichiatr Soc. 2009;18(01):23-33.

2. Huxley N, Baldessarini RJ. Disability and its treatment in bipolar disorder patients. Bipolar Disord. 2007;9(1-2):183-196.

3. Pini S, de Queiroz V, Pagnin D, et al. Prevalence and burden of bipolar disorders in European countries. Eur Neuropsychopharmacol. 2005; 15(4):425-434.

4. dell'aglio JC, Basso LA, Argimon II, Arteche A. Systematic review of the prevalence of bipolar disorder and bipolar spectrum disorders in population-based studies. Trends Psychiatry Psychother. 2013;35(2):99-105.

5. de Sousa Gurgel W, da Silva Carneiro AH, Barreto Rebouças D, et al. Prevalence of bipolar disorder in a HIV-infected outpatient population. AIDS Care. 2013;25(12):1499-1503.

6. Cruess DG, Evans DL, Repetto MJ, Gettes D, Douglas SD, Petitto JM. Prevalence, diagnosis, and pharmacological treatment of mood disorders in HIV disease. Biol Psychiatry. 2003;54(3):307-316.

7. Ellen SR, Judd FK, Mijch AM, Cockram A. Secondary mania in patients with HIV infection. Aust N Z J Psychiatry. 1999;33(3):353-360. 
8. Angst J, Gamma A. A new bipolar spectrum concept: a brief review. Bipolar Disord. 2002;4(s1):11-14.

9. Bolton JM, Robinson J, Sareen J. Self-medication of mood disorders with alcohol and drugs in the National Epidemiologic Survey on alcohol and related conditions. J Affect Disord. 2009;115(3):367-375.

10. Hariri AG, Karadag F, Gokalp P, Essizoglu A. Risky sexual behavior among patients in Turkey with bipolar disorder, schizophrenia, and heroin addiction. $J$ Sex Med. 2011;8(8):2284-2291.

11. Muhtadie L, Johnson SL, Carver CS, Gotlib IH, Ketter TA. A profile approach to impulsivity in bipolar disorder: the key role of strong emotions. Acta Psychiatr Scand. 2014;129(2):100-108.

12. Swann AC, Pazzaglia P, Nicholls A, Dougherty DM, Moeller FG. Impulsivity and phase of illness in bipolar disorder. $J$ Affect Disord. 2003;73(1-2):105-111.

13. Meade CS, Kershaw TS, Hansen NB, Sikkema KJ. Long-term correlates of childhood abuse among adults with severe mental illness: adult victimization, substance abuse, and HIV sexual risk behavior. AIDS Behav. 2009;13(2):207-216.

14. Abiola T, Udofia O, Zakari M. Psychometric properties of the 3-item Oslo social support scale among clinical students of Bayero University Kano, Nigeria. Malays J Psychiatry. 2013;22(2):32-41.

15. Moore DJ, Posada C, Parikh M, et al. HIV-infected individuals with co-occurring bipolar disorder evidence poor antiretroviral and psychiatric medication adherence. AIDS Behav. 2012;16(8):2257-2266.

16. Paterson DL, Swindells S, Mohr J, et al. Adherence to protease inhibitor therapy and outcomes in patients with HIV infection. Ann Intern Med. 2000;133(1):21-30.

17. Nakimuli-Mpungu E, Musisi S, Mpungu SK, Katabira E. Clinical presentation of bipolar mania in HIV-positive patients in Uganda. Psychosomatics. 2009;50(4):325-330.

18. Perantie DC, Brown ES. Corticosteroids, immune suppression, and psychosis. Curr Psychiatry Rep. 2002;4(3):171-176.

19. Kilbourne AM, Justice AC, Rabeneck L, Rodriguez-Barradas M, Weissman S; VACS 3 Project Team. General medical and psychiatric comorbidity among HIV-infected veterans in the post-HAART era. $J$ Clin Epidemiol. 2001;54 Suppl 1(12):S22-S28.

20. Frank E. Treating Bipolar Disorder: A Clinician's Guide to Interpersonal and Social Rhythm Therapy. New York: Guilford Press; 2007.

21. Bräunig P. Switch processes and rapid cycling in bipolar affective disorders, cycloid psychoses and nonsystematic schizophrenia. Psychopathology. 1990;23(4-6):291-302.

22. Perretta P, Akiskal HS, Nisita C, et al. The high prevalence of bipolar II and associated cyclothymic and hyperthymic temperaments in HIVpatients. J Affect Disord. 1998;50(2-3):215-224.

23. Smith DJ, Griffiths E, Kelly M, Hood K, Craddock N, Simpson SA. Unrecognised bipolar disorder in primary care patients with depression. Br J Psychiatry. 2011;199(1):49-56.

24. Berk M, Dodd S. Bipolar II disorder: a review. Bipolar Disord. 2005; $7(1): 11-21$.

25. Castilla-Puentes R, Secin R, Grau A, et al. A multicenter study of bipolar disorder among emergency department patients in Latin-American countries. Bipolar Disord. 2009;11:27.

26. Castelo MS, Hyphantis TN, Macêdo DS, et al. Screening for bipolar disorder in the primary care: a Brazilian survey. J Affect Disord. 2012; 143(1-3):118-124.

27. Hardoy MC, Cadeddu M, Murru A, et al. Validation of the Italian version of the "Mood Disorder Questionnaire" for the screening of bipolar disorders. Clin Pract Epidemiol Ment Health. 2005;1(1):8.

28. Parker G, Bayes A, Mcclure G, del Moral YR, Stevenson J. Clinical status of comorbid bipolar disorder and borderline personality disorder. Br J Psychiatry. 2016;209(3):209-215.
29. Shabani A, Koohi-Habibi L, Nojomi M, Chimeh N, Ghaemi SN, Soleimani N. The Persian Bipolar Spectrum Diagnostic Scale and Mood Disorder Questionnaire in screening the patients with bipolar disorder. Arch Iran Med. 2009;12(1):41-47.

30. Hirschfeld RM, Williams JB, Spitzer RL, et al. Development and validation of a screening instrument for bipolar spectrum disorder: the Mood Disorder Questionnaire. Am J Psychiatry. 2000;157(11):1873-1875.

31. Konuk N, Kiran S, Tamam L, Karaahmet E, Aydin H, Atik L. Duygudurum Bozuklukları Ölçeği?nin Türkçe Uyarlamasının Bipolar Bozukluk Taramasında Geçerliği [Validation of the Turkish version of the Mood Disorder Questionnaire for screening bipolar disorders]. Turkish J Psych. 2007; 18(2):147-54. Turkish.

32. Bohn MJ, Babor TF, Kranzler HR. The Alcohol Use Disorders Identification Test (AUDIT): validation of a screening instrument for use in medical settings. J Stud Alcohol. 1995;56(4):423-432.

33. Knight JR, Sherritt L, Harris SK, Gates EC, Chang G. Validity of brief alcohol screening tests among adolescents: a comparison of the audit, POSIT, CAGE, and CRAFFT. Alcohol Clin Exp Res. 2003;27(1):67-73.

34. Reinert DF, Allen JP. The alcohol use disorders identification test: an update of research findings. Alcohol Clin Exp Res. 2007;31(2):185-199.

35. Lopes M, Olfson M, Rabkin J, et al. Gender, HIV status, and psychiatric disorders: results from the National Epidemiologic Survey on Alcohol and Related Conditions. J Clin Psychiatry. 2012;73(3):384-391.

36. Chung KF, Tso KC, Cheung E, Wong M. Validation of the Chinese version of the Mood Disorder Questionnaire in a psychiatric population in Hong Kong. Psychiatry Clin Neurosci. 2008;62(4):464-471.

37. Rabkin JG. HIV and depression: 2008 review and update. Curr HIV/ AIDS Rep. 2008;5(4):163-171.

38. Nakimuli-Mpungu E, Musisi S, Mpungu SK, Katabira E. Primary mania versus HIV-related secondary mania in Uganda. Am J Psychiatry. 2006; 163(8):1349-1354.

39. Price RW, Brew B, Sidtis J, Rosenblum M, Scheck AC, Cleary P. The brain in AIDS: central nervous system HIV-1 infection and AIDS dementia complex. Science. 1988;239(4840):586-592.

40. Deeks SG, Lewin SR, Havlir DV. The end of AIDS: HIV infection as a chronic disease. Lancet. 2013;382(9903):1525-1533.

41. Escamilla MA, Zavala JM. Genetics of bipolar disorder. Dialogues Clin Neurosci. 2008;10(2):141.

42. Vayreda A, Antaki C. Social support and unsolicited advice in a bipolar disorder online forum. Qual Health Res. 2009;19(7):931-942.

43. Rutter M. Resilience in the face of adversity. Protective factors and resistance to psychiatric disorder. Br J Psychiatry. 1985;147(6): 598-611.

44. Liem R, Liem J. Social class and mental illness reconsidered: the role of economic stress and social support. J Health Soc Behav. 1978; 19(2):139-156.

45. Kessler RC, Chiu WT, Demler O, Merikangas KR, Walters EE. Prevalence, severity, and comorbidity of 12-month DSM-IV disorders in the National Comorbidity Survey Replication. Arch Gen Psychiatry. 2005;62(6):617-627.

46. Manji HK, Lenox RH. The nature of bipolar disorder. J Clin Psychiatry. 2000;61 Supp 13:42-57.

47. Ammassari A, Trotta MP, Shalev N, Marconi P, Antinori A. Beyond virological suppression: the role of adherence in the late HAART era. Antivir Ther. 2012;17(5):785-792.

48. Beach MC, Keruly J, Moore RD. Is the quality of the patient-provider relationship associated with better adherence and health outcomes for patients with HIV? J Gen Intern Med. 2006;21(6):661-665.

49. Tan X, Paten I, Chang J, et al. Review of four item Morisky Medication Adherence Scale ( MMAS-4) and eight item Morisky Medication Adherence Scale (MMAS-8). Inov Pharm. 2014;5(165):1-8. 


\section{Publish your work in this journal}

Neuropsychiatric Disease and Treatment is an international, peerreviewed journal of clinical therapeutics and pharmacology focusing on concise rapid reporting of clinical or pre-clinical studies on a range of neuropsychiatric and neurological disorders. This journa is indexed on PubMed Central, the 'PsycINFO' database and CAS, and is the official journal of The International Neuropsychiatric Association (INA). The manuscript management system is completely online and includes a very quick and fair peer-review system, which is all easy to use. Visit http://www.dovepress.com/testimonials.php to read real quotes from published authors.

\footnotetext{
Submit your manuscript here: http://www.dovepress.com/neuropsychiatric-disease-and-treatment-journal
} 